\title{
Erdheim Chester disease in a patient with Burkitt lymphoma: a case report and review of literature
}

\author{
Hany I. Sakr ${ }^{1}$, Kaila Buckley ${ }^{1 *} \mathbb{D}$, Robert Baiocchi ${ }^{2}$, Weiqiang John Zhao ${ }^{1}$ and Jessica A. Hemminger ${ }^{1}$
}

\begin{abstract}
Background: Erdheim Chester disease (ECD) is a rare, non-Langerhans cell histiocytosis characterized by widespread tissue infiltration by CD68-positive, CD1a-negative foamy histiocytes. ECD can be difficult to identify, and diagnosis relies on the presence of histiocytes with certain histologic and immunophenotypic features in an appropriate clinical and radiologic setting. Clinical signs and symptoms are variable depending on which organ systems are involved. Most patients have at least skeletal involvement with bone pain as well as fatigue. Other common manifestations include diabetes insipidus, cardiac, periaortic, or retro-orbital infiltration/fibrosis, kidney impairment, xanthelasmas, among others.
\end{abstract}

Case presentation: Herein, we describe a case of BRAF-mutation positive ECD in a patient with Burkitt lymphoma, and we review recent literature.

Conclusion: Underlying BRAF and other MAPK pathway mutations are identified in approximately $50 \%$ of cases of ECD, which aids in diagnosis as well as enables novel targeted treatments. ECD patients have an increased risk of myeloid neoplasms; however, unlike other histiocytoses, an association with lymphoproliferative disorders has not been recognized.

Keywords: Erdheim Chester disease, ECD, BRAF, Burkitt lymphoma, Histiocytosis, Lymphoproliferative disorders

\section{Background}

Erdheim Chester disease (ECD) is a rare histiocytosis characterized by tissue infiltration by CD68-positive, CD1anegative foamy histiocytes [1-4]. The disease mostly affects adults with a mean age of diagnosis in the fifth or sixth decade, though rare pediatric cases have been reported [5-8]. Of note, due to rarity and nonspecific clinical and biopsy findings, there is commonly a delay in diagnosis with a reported average time to diagnosis of 4.2 years [4]. There is a slight male predominance ( $\mathrm{M}: \mathrm{F}=1.5$ to $3: 1)$.

The disease has a wide spectrum of manifestations depending on distribution and degree of tissue involvement [4]. It is uncommon for ECD to involve only one organ system; thus, ECD patients typically have multiple signs and symptoms related to infiltration of multiple organ systems. The most common presenting clinical

\footnotetext{
*Correspondence: kailab979@aol.com

'Department of Pathology, The Ohio State University Wexner Medical Center, 410 W. 10th Ave, N\#308, Columbus, OH 43210, USA

Full list of author information is available at the end of the article
}

manifestations include bone pain that is symmetrically present involving long bones and diabetes insipidus due to infiltration of skull base and pituitary, respectively. Other common manifestations include renal impairment due to encasement of kidneys and involvement of the retroperitoneal space, cardiovascular disease due to encasement of the aorta and/or pseudotumor of the right atrioventricular groove, various endocrine abnormalities such as hypogonadism and hypothyroidism, and a variety of neurologic signs and symptoms, including mild cognitive impairment, cerebellar ataxia, and peripheral neuropathy. Two other characteristic lesions of ECD include periorbital xanthelasmas and retro-orbital involvement with resultant exophthalmos. Lungs are commonly involved but generally asymptomatic [3-19]. Although less common, ECD involvement of other organ sites, such as adrenal glands, gastrointestinal tract, thyroid, testis, breast, liver, and pancreas, have been reported [4, 20-25]. Radiologic imaging studies are useful to identify which organ systems may be involved. 
Histologic features of ECD include an atypical accumulation of histiocytes, which commonly have a foamy appearance due to cytoplasmic lipid vacuoles. Associated stromal fibrosis and admixed Touton giant cells are also frequently present. There can be admixed small, mature lymphocytes, neutrophils, eosinophils, and/or plasma cells. There is no emperipolesis, necrosis, nuclear atypia, or well-formed granulomas. The histiocytes in ECD are positive for CD68, CD163, and Factor XIIIa and negative for CD1a and langerin [1, 2, 4, 16, 19, 24]. S-100 expression is variable. An underlying $B R A F$ mutation (most commonly V600E) is seen in approximately half of ECD cases. Mutations in other MAPK pathway genes, including MAP2K1, NRAS, KRAS, ARAF, and PIK3CA, have also been reported in ECD $[4,26]$.

Herein we describe a case of $B R A F$-mutation positive ECD in a 48 year old male who was diagnosed with ECD after experiencing increasing weakness and failure to thrive after completing treatment for Burkitt lymphoma.

\section{Case presentation}

Clinical history

A 48 year old male with a past medical history of pituitary abnormality with central diabetes insipidus and hypogonadotrophic hypogonadism for eight years treated with desmopressin (DDAVP) and testosterone. He presented with shortness of breath, exertional dyspnea, and a four month history of weight loss and drenching night sweats. Computed tomography scan of the chest revealed a large mediastinal mass, and positron emission topography-computed tomography (PET/CT) scan demonstrated extensive, $2-\left[{ }^{18} \mathrm{~F}\right]$ fluoro-2-deoxy-D-glucose (FDG)-avid mediastinal and abdominal lymphadenopathy. A subsequent mediastinal lymph node biopsy showed Burkitt lymphoma with $\mathrm{t}(8 ; 14)$, and a staging bone marrow was negative for lymphoma. Burkitt lymphoma was staged as IVB. The patient received four cycles of R-CODOX/M/IVAC (Rituximab, Cyclophosphamide, Oncovin [Vincristine], Doxorubicin, Ifosfamide, Vepesid [etoposide], and Ara-C [Cytarabine] with methotrexate held due to pleural effusions and ifosfamide deleted in cycles 2 and 4 due to neurotoxicity. He also received involved field radiotherapy of 40 Gy in 20 fractions to residual mediastinal/subcarinal/pleural disease. During this time he was diagnosed with central hypothyroidism and began treatment with levothyroxine.

After completing the chemotherapeutic regimen, the patient experienced waxing and waning pain in the lower back and knees as well as bilateral leg weakness. Magnetic resonance imaging (MRI) scan of the knee showed infiltrative lesions within the distal femoral metaphysis/diaphysis and proximal tibial diaphysis; however, PET/CT scan was negative for PET-avid bone disease. A bone biopsy was suboptimal with nonspecific findings. Bilateral iliac crest biopsies revealed mildly hypercellular bone marrow with a small non-paratrabecular lymphohistiocytic aggregate. Over the next six months he showed progressive failure to thrive with new onset dysphagia. Neurologic and endocrine evaluations remained negative. MRI scans of the thoracic and lumbar spines showed progressive bone disease and extensive lung and pleural disease. The patient underwent bone marrow and pleural/lung biopsies.

\section{Biopsy findings}

The bone marrow biopsy showed normocellular bone marrow with preserved trilineage hematopoiesis and a few variably-sized, atypical histiocytic aggregates (Fig. 1). The histiocytes were epithelioid to spindled in appearance with a subset of foamy histiocytes. A rare multinucleated histiocyte was noted. The histiocytes were positive for CD68, CD163, factor XIIIa, and BRAF ${ }^{\mathrm{V} 600 \mathrm{E}}$ (clone VE1) and negative for CD1a, CD21, and CD23. There was no evidence of Burkitt lymphoma.

The pleural/lung lesion biopsy contained a small amount of tissue with a nonspecific fibrohistiocytic infiltrate. Genomic DNA was extracted and polymerase chain reaction (PCR) was performed for exon 15 of BRAF gene. The product was analyzed by pyrosequencing for mutations in codons 600 and 601 of BRAF with an analytic sensitivity of $5 \%$ for mutated allele. The BRAF p.V600E mutation (c.1799 T > A) was detected.

The histologic findings in combination with histiocyte phenotype, presence of $B R A F$ mutation, and clinical and radiologic data supported a diagnosis of ECD.

\section{Discussion}

ECD is a rare histiocytosis that was first described by William Chester in 1930 [27]. Histiocytoses are a heterogeneous group of diseases that historically have been classified as Langerhans cell or non-Langerhans cell subtypes with dendritic, macrophage/monocytic, and malignant forms [1]. However, recent insights have resulted in a proposed revised classification for histocytoses that includes five groups based on clinical, radiographic, pathologic, phenotypic, genetic, and/or molecular features [1]. In the proposed revised classification, Langerhans cell histiocytosis (LCH), ECD, and extracutaneous juvenile xanthogranuloma (JXG) are included in a group termed the "L group" since these entities share certain molecular and clinical features as well as can coexist in the same patient. In fact, nearly $20 \%$ of patients with ECD have concomitant $\mathrm{LCH}$ lesions $[1,19,28,29]$. The "L group" histiocytoses commonly show clonal mutations causing constitutive activation of the MAPK pathway with BRAF mutations being the most common. The other four groups in the proposed revised classification are the "C group" (cutaneous non- $\mathrm{LCH}$ ), the "R group" (Rosai Dorfman Disease [RDD] and variants), the " $M$ group" (primary and secondary malignant histiocytoses), 


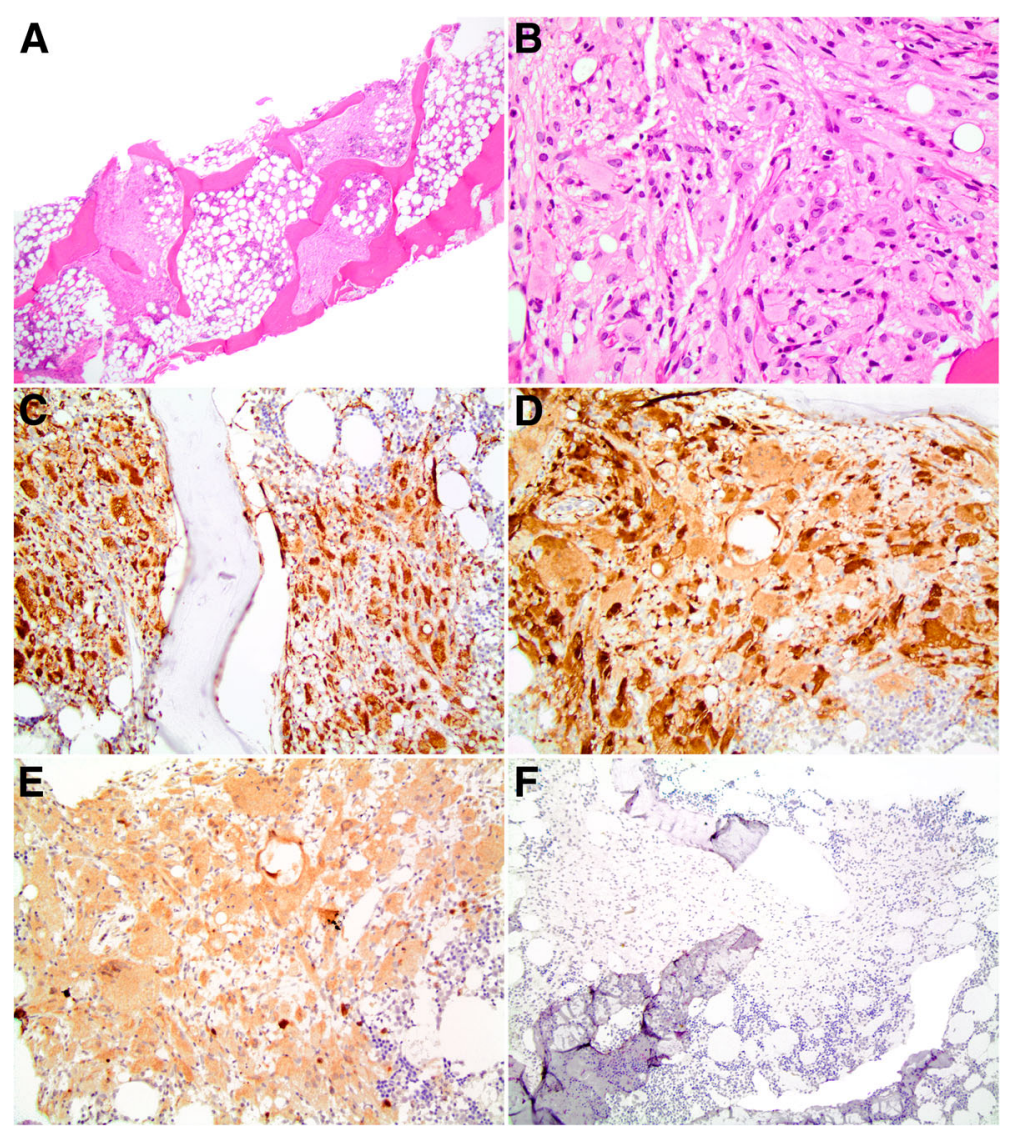

Fig. 1 (a) Bone marrow biopsy shows cellular bone marrow with trilineage hematopoiesis and patchy, atypical histiocytic aggregates (H\&E, 20x) (b) Atypical histiocytic aggregates are comprised of epithelioid to spindled-appearing histiocytes with a subset of foamy histiocytes (H\&E, 400x). The atypical histiocytes are diffusely positive for (c) CD68 (200X) (d) Factor XIlla (200x), and (e) BRAF V600E (clone VE1) and negative for (f) CD1a

and the "H group" (hemophagocytic lymphohistiocytosis and macrophage activation syndrome).

Given the variable and nonspecific clinical presentation, a diagnosis of ECD can be delayed and diagnostic possibilities based on clinical findings include sarcoidosis, malignancy, infection, autoimmune disorder NOS, large vessel vasculitis, IgG4-related disease, pituitary adenoma, Paget's disease of the bone, lysosomal storage disease, and multiple sclerosis [4]. Unfortunately, the histology is not specific either. The presence of foamy histiocytes with Touton giant cells is helpful in identifying ECD; however, additional immunophenotyping and molecular studies as well as clinical and radiologic correlation are necessary for a definitive diagnosis. The main histologic differential diagnosis includes nonspecific xanthogranulomatous inflammation, granulomatous inflammation associated with infections, non-histiocytic hematopoietic neoplasms, and other histiocytoses, including LCH, RDD, JXG, and histiocytic sarcoma. Immunophenotyping can be used to distinguish ECD from other diseases in the differential diagnosis (Table 1). Particularly, CD1a and langerin will be positive in $\mathrm{LCH}$ and negative in ECD. S-100 is typically strongly positive in RDD. Also, RDD is characterized by emperipolesis and negativity for Factor XIIIa. Since JXG and ECD are morphologically and immunophenotypically identical, their differentiation from one another mostly relies on the clinical presentation and radiologic findings. Cases

Table 1 Summary of immunohistochemical staining pattern for ECD differential diagnoses

\begin{tabular}{llllll}
\hline & ECD & LCH & ICH & RDD & JXG \\
\hline CD68 & + & + & $+/-$ & + & + \\
CD163 & + & + & $+/-$ & + & + \\
FXIlla & + & - & - & - & + \\
CD1a & - & + & + & - & - \\
CD207 (Langerin) & - & + & - & - & - \\
S100 & $+/-$ & + & + & + & - \\
CD4 & + & + & + & + & + \\
Lysozyme & + & + & + & + & + \\
BRAFV600E & $+/-$ & $+/-$ & $+/-$ & - & $+/-$ \\
\hline
\end{tabular}

ECD Erdheim Chester Disease, ICH Indeterminate cell histiocytosis, JXG Juvenile xanthogranuloma, LCH Langerhans Cell Histiocytosis, RDD Rosai-Dorfman Disease 
of extracutaneous or widely-disseminated JXG are usually accepted as ECD [1]. ECD can typically be differentiated from malignant lesions since ECD lacks cytologic atypia, necrosis, and mitoses. Mycobacterial and fungal stains as well as cultures can be performed to exclude an infectious etiology. The lack of well-formed granulomas makes sarcoidosis less likely.

Unlike RDD and JXG, which can have a benign clinical course and exhibit spontaneous regression, ECD progresses without treatment [4]. The traditional first line treatment for ECD is interferon alpha (IFN- $\alpha$ ) or pegylated IFN- $\alpha$ [30]. A 2011 study by Haroche and colleagues showed that treatment with IFN- $\alpha$ or pegylated IFN- $\alpha$ was a major independent predictor of survival [31]. Unfortunately, IFN-a therapy is often poorly tolerated, however, a wide variety of other regimens have demonstrated disease activity, including cytokine-neutralizing antibodies, corticosteroids, chemotherapy, imatinib, cladribine, among others [4, 26, 32]. Recent studies utilizing BRAF and MEK inhibitors (e.g. vermurafenib, dabrafenib, trametinib) have shown efficacy in treating ECD with limited toxicity [29, 30, 33, 34].

The existence of both ECD and Burkitt lymphoma in this patient is interesting. It is recognized that histiocytic and dendritic cell neoplasms can be clonally related to leukemias and lymphomas, possibly due to derivation from a common pluripotent precursor, anaplastic progression with aberrant expression of some histiocyte/dendritic cell markers, or by "transdifferentiation" $[1,35,36]$. The typical scenario is a patient with a low grade B cell lymphoma such as follicular lymphoma and metachronous or synchronous histiocytic sarcoma or LCH. Clonal relationships have been proven at a molecular level by detecting the same immunoglobulin rearrangement and/or certain genetic abnormalities, such as $t(14 ; 18)$, in the histiocytosis and lymphoproliferative disorder [1, 35, 36]. Recently, Papo et al. reported an increased prevalence of myeloid neoplasms, specifically myeloproliferative neoplasms, myelodysplastic syndrome, and chronic myelomonocytic leukemia (CMML), in adults with non-Langerhans cell histiocytoses, including ECD alone or mixed histiocytosis (defined as ECD plus LCH or ECD plus LCH and RDD) [37]. In these patients the ECD commonly harbored a BRAFV600E mutation and the myeloid neoplasm commonly had JAK2V617F and/or other commonly mutated genes in myeloid neoplasms. In one patient, the same NRAS mutation was detected in both ECD and CMML.

Although there can be clonal relationships between certain histiocytoses and lymphoproliferative disorders and there is an increased risk of myeloid neoplasms in ECD patients, there is currently no known association between lymphoproliferative disorders and ECD. Other than our patient, there have only been a few reports of lymphoma in ECD patients. Papo et al. noted only two patients with lymphoma in their cohort of 189 cases of $\mathrm{ECD} /$ mixed histiocytosis. Also, there was a report describing marginal zone lymphoma in a patient with ECD [38]. Thus, lymphomas can occur in patients with ECD; however, a defined relationship has not been established, and the rare coexistence of ECD and lymphoma may be incidental.

\section{Conclusion}

The diagnosis of ECD can be difficult and relies on clinical, histologic, phenotypic, radiologic, and molecular correlation. Clinical presentation is variable depending on organ system involvement; however, in patients presenting with bone pain and diabetes insipidus, the possibility of ECD should be considered, and imaging studies and biopsy may be useful. ECD histology is nonspecific, but characterized by an accumulation of foamy histiocytes with Touton giant cells. Unlike LCH, the histiocytes in ECD are Factor XIIIa positive and CD1a and langerin negative. Approximately $50 \%$ of ECD will have an underlying BRAF V600E mutation; thus, BRAF and MEK inhibitors are attractive therapeutic options. Lastly, ECD patients have an increased association with $\mathrm{LCH}$ as well as myeloid neoplasms.

\section{Abbreviations \\ CMML: Chronic myelomonocytic leukemia; DDAVP: Desmopressin; ECD: Erdheim Chester disease; IFN-a: Interferon alpha; JXG: Juvenile xangthogranuloma; LCH: Langerhans cell histiocytosis; PET/CT: Positron emission topography-computed tomography; R-CODOX/M/IVAC: Rituximab, Cyclophosphamide, Oncovin [Vincristine], Doxorubicin, Ifosfamide, Vepesid [etoposide], and Ara-C [Cytarabine]; RDD: Rosai Dorfman disease}

\section{Acknowledgements}

Not applicable

Funding

None

\section{Availability of data and materials}

Data sharing is not applicable to this article as no datasets were generated or analyzed during the current study.

\section{Authors' contributions}

HS researched and wrote the majority of the paper. KB assisted with research and writing, particularly the discussion/conclusion portion. JH provided the interesting case that we reported, as well as guidance and editing throughout the writing process. WJZ assisted with interpreting molecular techniques. RB provided clinical knowledge and history on the patient. All authors read and approved the final manuscript.

\section{Ethics approval and consent to participate}

N/A (this is a case report that references de-identified patient data and histopathologic images. The patient signed a consent form).

\section{Consent for publication}

Written informed consent for publication of their clinical details and/or clinical images was obtained from the patient. A copy of the consent form is available for review by the Editor of this journal.

Competing interests

The authors declare that they have no competing interests. 


\section{Publisher's Note}

Springer Nature remains neutral with regard to jurisdictional claims in published maps and institutional affiliations.

\section{Author details}

'Department of Pathology, The Ohio State University Wexner Medical Center, 410 W. 10th Ave, N\#308, Columbus, OH 43210, USA. ²Department of Internal Medicine (Hematology), The Ohio State University Wexner Medical Center, Columbus, $\mathrm{OH}$, USA.

Received: 19 September 2018 Accepted: 12 November 2018 Published online: 24 November 2018

\section{References}

1. Emile JF, Abla O, Fraitag S, Horne A, Haroche J, Donadieu J, RequenaCaballero L, Jordan MB, Abdel-Wahab O, Allen CE, Charlotte F, Diamond EL, Egeler RM, Fischer A, Herrera JG, Henter Jl, Janku F, Merad M, Picarsic J, Rodriguez-Galindo C, Rollins BJ, Tazi A, Vassallo R, Weiss LM. Revised classification of histiocytoses and neoplasms of the macrophage-dendritic cell lineages. Blood. 2016:127:2672-81.

2. Mazor RD, Manevich-Mazor M, Kesler A, Aizenstein O, Eshed I, Jaffe R, Pessach Y, Goldberg L, Sprecher E, Yaish I, Gural A, Ganzel C, Shoenfeld Y. Clinical considerations and key issues in the management of patients with Erdheim-Chester disease: a seven case series. BMC Med. 2014;12:221.

3. Campochiaro C, Tomelleri A, Cavalli G, Berti A, Dagna L. Erdheim-Chester disease. Eur J Intern Med. 2015:26(4):223-9.

4. Estrada-Veras Jl, O'Brien KJ, Boyd LC, Dave RH, Durham B, Xi L, Malayeri AA, Chen MY, Gardner PJ, Alvarado-Enriquez JR, Shah N, Abdel-Wahab O, Gochuico BR, Raffeld M, Jaffe ES, Gahl WA. The clinical spectrum of Erdheim-Chester disease: an observational cohort study. Blood Adv. 2017;1(6):357-66.

5. Kumandaş S, Kurtsoy A, Canöz O, Patiroğlu T, Yikilmaz A, Per H. Erdheim Chester disease: cerebral involvement in childhood. Brain and Development 2007:29(4):227-30

6. Vallonthaiel AG, Mridha AR, Gamanagatti S, Jana M, Sharma MC, Khan SA, Bakhshi S. Unusual presentation of Erdheim-Chester disease in a child with acute lymphoblastic leukemia. World J Radiol. 2016;8(8):757-63.

7. Tran TA, Fabre M, Pariente D, Craiu I, Haroche J, Charlotte F, Eid P, Durrbach A, Taoufik Y, Kone-Paut I. Erdheim-Chester disease in childhood: a challenging diagnosis and treatment. J Pediatr Hematol Oncol. 2009:31(10):782-6.

8. Váradi Z, Bánusz R, Csomor J, Kállay K, Varga E, Kertész G, Csóka M. Effective BRAF inhibitor vemurafenib therapy in a 2-year-old patient with sequentially diagnosed Langerhans cell histiocytosis and Erdheim-Chester disease. Onco Targets Ther. 2017;10:521-6.

9. Gianfreda D, Palumbo AA, Rossi E, Buttarelli L, Manari G, Martini C, De Filippo M, Vaglio A. Cardiac involvement in Erdheim-Chester disease: an MR study. Blood. 2016:128(20):2468-71.

10. Haroche J, Cluzel P, Toledano D, Montalescot G, Touitou D, Grenier PA, Piette JC, Amoura Z. Images in cardiovascular medicine. Cardiac involvement in Erdheim-Chester disease: magnetic resonance and computed tomographic scan imaging in a monocentric series of 37 patients. Circulation. 2009;119(25):e597-8.

11. Merli E, Savelli F, Lovato L, Zompatori M. Cardiac involvement in ErdheimChester disease: echocardiographic appearance and value of cardiac MRI. Eur Heart J Cardiovasc Imaging. 2012;13(2):198

12. Oweity T, Scheithauer BW, Ching HS, Lei C, Wong KP. Multiple system Erdheim-Chester disease with massive hypothalamic-sellar involvement and hypopituitarism. J Neurosurg. 2002;96(2):344-51.

13. Sedrak P, Ketonen L, Hou P, Guha-Thakurta N, Williams MD, Kurzrock R, Debnam JM. Erdheim-Chester disease of the central nervous system: new manifestations of a rare disease. Am J Neuroradiol. 2011;32(11):2126-31.

14. Chung JH, Park MS, Shin DH, Choe KO, Kim SK, Chang J, Kim SK, Kim YS Pulmonary involvement in Erdheim-Chester disease. Respirology. 2005;10(3):389-92.

15. Arnaud L, Pierre I, Beigelman-Aubry C, Capron F, Brun AL, Rigolet A, Girerd X, Weber N, Piette JC, Grenier PA, Amoura Z, Haroche J. Pulmonary involvement in Erdheim-Chester disease: a single-center study of thirty-four patients and a review of the literature. Arthritis Rheum. 2010 Nov;62(11):3504-12.

16. Cavalli G, Guglielmi B, Berti A, Campochiaro C, Sabbadini MG, Dagna L. The multifaceted clinical presentations and manifestations of Erdheim-Chester disease: comprehensive review of the literature and of 10 new cases. Ann Rheum Dis. 2013;72(10):1691-5.
17. Wimpissinger TF, Schernthaner G, Feichtinger H, Stackl W. Compression of kidneys in Erdheim-Chester disease of retroperitoneum: open surgical approach. Urology. 2005;65:798.

18. Volpicelli ER, Doyle L, Annes JP, Murray MF, Jacobsen E, Murphy GF, Saavedra AP. Erdheim-Chester disease presenting with cutaneous involvement: a case report and literature review. J Cutan Pathol. 2011;38(3):280-5.

19. Johnson WT, Patel P, Hernandez A, Grandinetti LM, Huen AC, Marks S, Ho J, Monaco SE, Jaffe R, Picarsic J. Langerhans cell histiocytosis and Erdheim-Chester disease, both with cutaneous presentations, and papillary thyroid carcinoma all harboring the BRAF(V600E) mutation. J Cutan Pathol. 2016;43(3):270-5.

20. Haroche J, Amoura Z, Touraine P, Seilhean D, Graef C, Birmele B, Wechsler B, Cluzel P, Grenier PA, Piette JC. Bilateral adrenal infiltration in ErdheimChester disease. Report of seven cases and literature review. J Clin Endocrinol Metab. 2007;92:2007-12.

21. Pan A, Doyle T, Schlup M, Lubcke $R$, Schultz M. Unusual manifestation of Erdheim-Chester disease. BMC Gastroenterol. 2011;11:77.

22. Ivan D, Neto A, Lemos L, Gupta A. Erdheim-Chester disease: a unique presentation with liver involvement and vertebral osteolytic lesions. Arch Pathol Lab Med. 2003:127:e337-9.

23. Sheu S-Y, Wenzel RR, Kersting C, Merten R, Otterbach F, Schmid KW. Erdheim-Chester disease: case report with multisystemic manifestations including testes, thyroid, and lymph nodes, and a review of literature. J Clin Pathol. 2004:57(11):1225-8.

24. Roverano S, Gallo J, Ortiz A, Migliore N, Eletti M, Paira S. Erdheim-Chester disease: description of eight cases. Clin Rheumatol. 2016;35(6):1625-9.

25. Guo S, Yan Q, Rohr J, Wang Y, Fan L, Wang Z. Erdheim-Chester disease involving the breast-a rare but important differential diagnosis. Hum Pathol. 2015 Jan;46(1):159-64

26. Haroun F, Millado K, Tabbara I. Erdheim-Chester disease: comprehensive review of molecular profiling and therapeutic advances. Anticancer Res. 2017;37(6):2777-83.

27. Chester W. Uber lipoidgranulomatose. Virchows Arch Pathol Anat. 1930;279: 561-602.

28. Hervier B, Haroche J, Arnaud L, Charlotte F, Donadieu J, N'eel A, Lifermann F, Villabona C, Graffin B, Hermine O, Rigolet A, Roubille C, Hachulla E, Carmoi T, B'ezier M, Meignin V, Conrad M, Marie L, Kostrzewa E, Michot JM, Barete S, Taly V, Cury K, Emile JF, Amoura Z. Association of both Langerhans cell histiocytosis and Erdheim-Chester disease linked to the BRAFV600E mutation. Blood. 2014;124(7):1119-26.

29. Haroche J, Cohen-Aubart F, Emile JF, Arnaud L, Maksud P, Charlotte F, Cluzel P, Drier A, Hervier B, Benameur N, Besnard S, Donadieu J, Amoura Z. Dramatic efficacy of vemurafenib in both multisystemic and refractory Erdheim-Chester disease and Langerhans cell histiocytosis harboring the BRAF V600E mutation. Blood. 2013;121(9):1495-500.

30. Haroche J, Arnaud L, Cohen-Aubart F, Hervier B, Charlotte F, Emile JF, Amoura Z. Erdheim-Chester disease. Rheum Dis Clin N Am. 2013;39(2):299-311.

31. Arnaud L, Hervier B, Neel A, Hamidou MA, Kahn JE, Wechsler B, Pérez-Pastor G, Blomberg B, Fuzibet JG, Dubourguet F, Marinho A, Magnette C, Noel V, Pavic M, Casper J, Beucher AB, Costedoat-Chalumeau N, Aaron L, Salvatierra J, Graux C, Cacoub P, Delcey V, Dechant C, Bindi P, Herbaut C, Graziani G, Amoura Z, Haroche J. CNS involvement and treatment with interferon-alpha are independent prognostic factors in Erdheim-Chester disease: a multicenter survival analysis of 53 patients. Blood. 2011;117:2778-82.

32. Diamond EL, Dagna L, Hyman DM, Cavalli G, Janku F, Estrada-Veras J, Ferrarini M, Abdel-Wahab O, Heaney ML, Scheel PJ, Feeley NK, Ferrero E, McClain KL, Vaglio A, Colby T, Arnaud L, Haroche J. Consensus guidelines for the diagnosis and clinical management of Erdheim-Chester disease. Blood. 2014:124(4):483-92

33. Hyman DM, Puzanov I, Subbiah V, Faris JE, Chau I, Blay JY, Wolf J, Raje NS, Diamond EL, Hollebecque A, Gervais R, Elez-Fernandez ME, Italiano A, Hofheinz RD, Hidalgo M, Chan E, Schuler M, Lasserre SF, Makrutzki M, Sirzen F, Veronese ML, Tabernero J, Baselga J. Vemurafenib in multiple nonmelanoma cancers with BRAF V600 mutations. N Engl J Med. 2015;373(8):726-36.

34. Nordmann TM, Juengling FD, Recher M, Berger CT, Kalbermatten D, Wicki A Paasinen-Sohns A, Cathomas G, Tzankov A, Daikeler T. Trametinib after disease reactivation under dabrafenib in Erdheim-Chester disease with both BRAF and KRAS mutations. Blood. 2017;129(7):879-82.

35. Shao H, Xi L, Raffeld M, Feldman AL, Ketterling RP, Knudson R, RodriguezCanales J, Hanson J, Pittaluga S, Jaffe ES. Clonally related histiocytic/ dendritic cell sarcoma and chronic lymphocytic leukemia/small lymphocytic lymphoma: a study of seven cases. Mod Pathol. 2011;24(11):1421-32. 
36. Feldman AL, Arber DA, Pittaluga S, Martinez A, Burke JS, Raffeld M, Camos M, Warnke R, Jaffe ES. Clonally related follicular lymphomas and histiocytic/ dendritic cell sarcomas: evidence for transdifferentiation of the follicular lymphoma clone. Blood. 2008:111(12):5433-9.

37. Papo M, Diamond EL, Cohen-Aubart F, Emile JF, Roos-Weil D, Gupta N, Durham BH, Ozkaya N, Dogan A, Ulaner GA, Rampal R, Kahn JE, Sené T,

Charlotte F, Hervier B, Besnard C, Bernard OA, Settegrana C, Droin N, HéliasRodzewicz Z, Amoura Z, Abdel-Wahab O, Haroche J. High prevalence of myeloid neoplasms in adults with non-Langerhans cell histiocytosis. Blood. 2017;130(8):1007-13.

38. Pavlidakey PG, Mohanty A, Kohler LJ, Meyerson HJ. Erdheim-Chester disease associated with marginal zone lymphoma and monoclonal Proteinemia. Case Rep Hematol. 2011;2011:941637.

Ready to submit your research? Choose BMC and benefit from:

- fast, convenient online submission

- thorough peer review by experienced researchers in your field

- rapid publication on acceptance

- support for research data, including large and complex data types

- gold Open Access which fosters wider collaboration and increased citations

- maximum visibility for your research: over $100 \mathrm{M}$ website views per year

At BMC, research is always in progress.

Learn more biomedcentral.com/submissions 